\title{
$\nabla$
}

\section{Prevalence of metabolic syndrome in patients with psoriasis: a hospital- based cross-sectional study ${ }^{*}$}

\author{
Danijela Milčić ${ }^{1,2}$ \\ Sonja Vesić1,2 \\ Jelena Marinković ${ }^{4}$ \\ Janko Jankovićs
}

\author{
Slavenka Janković3 \\ Mirjana Milinkovićn ${ }^{1}$ \\ Andja Ćirković ${ }^{4}$
}

DOI: http:/ /dx.doi.org/10.1590/abd1806-4841.20175178

\begin{abstract}
BACKGROUND: Emerging epidemiological evidence suggests independent associations between psoriasis and metabolic syndrome. Objectives: The aim of the study was to examine the prevalence of metabolic syndrome and its components in patients with psoriasis, and to assess which factors may predict metabolic syndrome in these patients.

METHODs: A hospital-based, cross-sectional study with 244 psoriatic patients and 163 control subjects with skin diseases other than psoriasis was conducted at the Clinic of Dermatovenerology, Clinical Center of Serbia, Belgrade, from October 2011 to October 2012. Metabolic syndrome was defined using the revised National Cholesterol Education Program Adult Treatment Panel III. Severity of psoriasis was measured by Psoriasis Area and Severity Index and Body Surface Area.

RESULTS: The adjusted odds ratios (ORs) and 95\% confidence intervals (CI) for psoriasis patients vs. non-psoriasis patients were 2.66 (95\% CI, 1.58-4.42) for metabolic syndrome, 3.81 (95\% CI, 2.30-6.31) for hypertension, 2.29 (95\% CI, 1.39-3.78) for central obesity, 1.92 (95\% CI, 1.08-3.41) for hyperglycemia, 1.87 (95\% CI 1.18-2.96) for low high-density lipoprotein cholesterol level, and 1.42 (95\% CI, 0.87-1.04) for hypertrigliceridemia. We failed to find any statistically significant association between the metabolic syndrome and clinical severity of psoriasis. Later onset and longer duration of psoriasis were predicting factors for metabolic syndrome in our patients. Study limitations: The cross-sectional design of the study does not allow us to draw directional causal inferences concerning the association between psoriasis and metabolic syndrome. Factors such as diet, alcohol consumption or mental health, which have not been evaluated in this study, may be confounders in this relation.

CONCLUSION: A higher prevalence of metabolic syndrome and its components in patients with psoriasis than in controls, regardless of disease severity, emphasizes the need for early treatment and follow-up of all psoriatic patients with respect to metabolic diseases.
\end{abstract}

Keywords: Cardiovascular diseases; Metabolic Syndrome; Psoriasis

\section{INTRODUCTION}

Psoriasis is a common, chronic, immune-mediated inflammatory skin disease that affects approximately 2-3\% of the world population. ${ }^{1}$ Recent findings suggest that previous concept considering psoriasis as a "disease of healthy people" should be revised into "psoriasis as a complex and multisystemic disease" with a profound negative impact on a patient's quality of life..$^{2-5}$ The existing literature shows that psoriasis is associated with an increased prevalence of cardiovascular risk factors, increased risk of myocardial infarction and stroke, and an excess of cardiovascular mortality. ${ }^{6-10}$

The metabolic syndrome (MetS) is a cluster of cardiovascular risk factors including abdominal obesity, hypertension, atherogenic dyslipidemia (raised triglycerides and low concentrations of high-density lipoprotein cholesterol [HDL-C] level), and glucose intolerance which has been shown to predict cardiovascular disease (CVD) and diabetes mellitus (DM). ${ }^{11}$

Received on 26.09.2015

Approved by the Advisory Board and accepted for publication on 06.03.2016

* Study conducted at the Clinic of Dermatovenereology, Clinical Center of Serbia - Belgrade, Serbia.

Financial support: This work was supported by the Ministry of Education, Science and Technological Development of the Republic of Serbia, project No. 175025.

Conflict of interest: None.

Department of Dermatovenereology, Faculty of Medicine, University of Belgrade - Belgrade, Serbia.

Clinic of Dermatovenereology, Clinical Center of Serbia - Belgrade, Serbia.

Institute of Epidemiology, Faculty of Medicine, University of Belgrade - Belgrade, Serbia.

Institute of Medical Statistics and Informatics, Faculty of Medicine, University of Belgrade - Belgrade, Serbia.

Institute of Social Medicine, Faculty of Medicine, University of Belgrade - Belgrade, Serbia.

C2017 by Anais Brasileiros de Dermatologia 
Emerging epidemiological evidence suggests a significant association between psoriasis and MetS and its components. ${ }^{12-15}$ The link between psoriasis and the MetS has not been completely elucidated but it seems that both entities have common pathophysiology with underlying chronic inflammatory status. ${ }^{11,16}$

The aim of this study was to investigate the prevalence of MetS and its components in patients with psoriasis and to compare them with control subjects without psoriasis. We also aimed to determine relation between disease severity and prevalence of MetS and its components, and to assess the prediction of MetS in psoriatic patients.

\section{METHODS}

\section{Patients and study design}

A cross-sectional study was conducted at the Clinic of Dermatovenerology, Clinical Center of Serbia, Belgrade, over a one-year period, from October 2011 to October 2012. The study included 244 consecutive patients with psoriasis vulgaris and 163 controls hospitalized or treated as outpatients. The inclusion criteria for the cases were $\geq 18$ years of age, and clinical diagnosis of chronic plaque psoriasis (lasting at least 6 months) established by experienced dermatologists. The patients with psoriasis who received systemic treatment for psoriasis, including acitretin, cyclosporine, methotrexate, phototherapy or biologics for at least 1 month before enrolment were excluded. The control group consisted of patients aged $\geq 18$ years without a diagnosis of psoriasis or any autoimmune or chronic inflammatory dermatological disease. It included patients with diagnoses of skin and nail mycoses, seborrheic keratosis, skin tags, viral warts, melanocytic nevi, etc.

A short structured questionnaire was used to collect data regarding age, gender, smoking habits, physical activity, age of psoriasis onset, duration of the disease and drug treatment with antihypertensive, hypo-glycemic, or lipid-lowering drugs.

Smoking status was categorized as never, former, and current. Physical activity was measured with a question: "In your leisure time, how often do you do physical exercise for at least $30 \mathrm{~min}$ that makes you at least mildly short of breath or perspire?" Those who participated in physical activity four times or more per week were categorized as active, those who exercised less than four times a week but at least 2-3 times a month were categorized as moderately (in)active and those who exercised several times a year or did not exercise at all were categorized as inactive.

For the assessment of psoriasis severity Psoriasis Area and Severity Index (PASI) and Body Surface Area (BSA) were used. Psoriasis was considered as mild if the PASI score was $<10$, moderate if the PASI score was between 10 and 20, and severe if the PASI score was $>20 .{ }^{17}$ According to BSA, in patients with BSA $<10 \%$ psoriasis was considered as localized, and in those with BSA $>10 \%$ as disseminated. ${ }^{18}$

Anthropometric measures recorded in this study were weight, height and waist circumference. Measures of weight (kilograms) and height (meters) were assessed using a standard physician's scale and a stadiometer, respectively. The body mass index (BMI) was calculated as weight in kilograms divided by squared height in meters $\left(\mathrm{kg} / \mathrm{m}^{2}\right)$. BMI between $25 \mathrm{~kg} / \mathrm{m}^{2}$ and $30 \mathrm{~kg} / \mathrm{m}^{2}$ was defined as overweight and $\mathrm{BMI} \geq 30 \mathrm{~kg} / \mathrm{m}^{2}$ was considered as obesi- ty. The waist circumference was measured by placing the measuring tape horizontally around the abdomen at level of the upper part of the hipbone. Blood pressure was recorded as the mean of two measurements after subjects had been sitting for 15 minutes.

Glycaemia, trygliceridemia, HDL-C and C-reactive protein (CRP) levels were measured using standard biochemical procedures, after taking a venous blood sample from patients who had fasted overnight for at least $8 \mathrm{~h}$.

MetS was defined using revised National Cholesterol Education Program Adult Treatment Panel (NCEP ATP) III criteria. ${ }^{11}$ Participants with 3 or more of the 5 following criteria: abdominal obesity (waist circumference $\geq 102 \mathrm{~cm}$ in men or $\geq 88 \mathrm{~cm}$ in women); hypertriglyceridemia (triglycerides $\geq 1.7 \mathrm{mmol} / \mathrm{l}$ ); low levels of HDL-C ( $<1.03 \mathrm{mmol} / 1$ in men or $<1.29 \mathrm{mmol} / 1$ in women); high blood pressure $(\geq 130 / 85 \mathrm{mmHg}$ ) or receiving drug therapy for hypertension; and high fasting glucose levels $(\geq 5.6 \mathrm{mmol} / \mathrm{l})$ or presence of DM were defined as having MetS.

The study protocol was approved by the Ethics Committee of the Clinical Center of Serbia and Ethics Committee of the Faculty of Medicine, University of Belgrade, Serbia. Written informed consent was obtained from all participants.

\section{Statistical analysis}

Categorical variables were expressed as counts and percentages, while continuous variables were presented as mean \pm standard deviation (SD). Subgroup analyses on demographic and clinical characteristics of patients and controls were conducted. Using the chi-square test for categorical variables and t-test for continuous variables associations between different variables were tested.

Odds ratios (ORs) and 95\% Confidence intervals (CIs) for the association between psoriasis and disease extent and the components of the MetS were calculated using multivariate logistic regression. Adjusted ORs were determined by adjusting for confounders such as age and sex. Multivariate logistic regression analysis (the Enter method) was also used to predict MetS in psoriatic patients. The dependent variable was absence/presence of MetS, while the independent variables included age of psoriasis onset, duration of psoriasis, PASI and physical activity. The selection of independent variables was based on literature review. ${ }^{18-21}$ Possible correlation between them was estimated by VIF (variance inflation factor). Also, the model was tested for pair-wise interaction between covariates. Interactions with sex and age were considered. Once the model was fitted to the data, the adequacy of fit was assessed by the Hosmer-Lemeshow (H-L) test as well as with AUC (Area under the ROC curve).

A two-tailed probability value of 0.05 or less was considered significant. All statistical analyses were performed with the Statistical Package for the Social Sciences, version 20.0 (SPSS Inc., Chicago, IL, USA).

\section{RESULTS}

The descriptive data of 244 patients with psoriasis compared to 163 control subjects are shown in table 1 .

The mean age was significantly higher for cases than for controls (53.54 vs. 43.69). There were more males than females in 
the study group. Smoking and lack of physical activities were more frequently observed in psoriatic patients. Waist circumference, triglycerides, systolic and diastolic blood pressure, and CRP levels were significantly higher in the patients with psoriasis compared with control subjects, while HDL-C level was higher in controls. There were no significant differences regarding BMI and fasting blood glucose.

The prevalence of MetS and its components in patients with overall, mild, moderate and severe psoriasis and in control subjects are shown in table 2.

All the components of MetS, except low level of HDL-C, were significantly higher in psoriatic group compared with controls: abdominal obesity ( $46.7 \%$ vs. $26.4 \%$ ), raised triglyceride levels (38.1\% vs. 24.5 ), high blood pressure (67.2\% vs. 25.8 ), and raised glucose or type $2 \mathrm{DM}$ (31.6\% vs. 13.5). Statistically significant difference in the level of low HDL-C was found only between patients with severe psoriasis and controls. In contrast, raised triglycerides compared to controls were more prevalent in patients with mild and moderate psoriasis, but not in the patients with severe psoriasis. The prevalence of MetS and the mean number of MetS components were significantly higher in patients with mild, moderate and severe form of psoriasis than in the control group.

After adjusting for age, gender and other components of the MetS, the strongest association between a single component of the MetS and psoriasis overall was found with raised blood pressure (adj. OR 3.81, 95\% CI 2.30-6.31) followed by obesity (adj. OR 2.29, 95\% CI 1.39-3.78) with the associations being strongest in the group with moderate psoriasis. The association with low HDL-C demonstrated a dose-response relation, with a $34 \%$ increase in low HDL-C in those with mild psoriasis (adj. OR 1.34, 95\% CI 0.74-2.43), 88\% increase in low HDL-C in those with moderate psoriasis (adj. OR 1.88, 95\% CI 1.05-3.37), with the biggest increase in low HDL-C in those with severe psoriasis (adj. OR 2.63, 95\% CI 1.45-4.77). Raised glucose level was also associated with psoriasis independent of obesity, with a $92 \%$ increased odds ratio of overall raised glucose (adj. OR 1.92, 95\% CI 1.08-3.41) and the strongest association in the group with the most severe psoriasis. Adjusted OR for MetS in psoriatic patients compared with controls was 2.66 (95\% CI, 1.58-4.42). There were no statistically significant differences between ORs for mild, moderate and severe psoriasis (Table 3).

TABLE 1: Characteristics of study population

\begin{tabular}{|c|c|c|c|}
\hline Characteristic & Cases $(\mathrm{n}=244)$ & Controls $(n=163)$ & $\mathbf{P}$ \\
\hline Age (years), mean \pm SD & $53.54 \pm 15.16$ & $43.69 \pm 14.68$ & $<0.001$ \\
\hline Sex (males/females) & $160 / 84$ & $53 / 110$ & $<0.001$ \\
\hline \multicolumn{4}{|l|}{ Smoking status, $\mathrm{n}(\%)$} \\
\hline Never smoker & $70(28.7)$ & $92(56.4)$ & \\
\hline Former smoker & $71(29.1)$ & $32(19.6)$ & \\
\hline Current smoker & $103(42.2)$ & $39(23.9)$ & $<0.001$ \\
\hline \multicolumn{4}{|l|}{ Physical activity, n (\%) } \\
\hline Inactive & $147(60.2)$ & $70(42.9)$ & 0.003 \\
\hline Moderate active & $71(29.1)$ & $66(40.5)$ & \\
\hline Active & $26(10.7)$ & $27(16.6)$ & \\
\hline Body mass index $(\mathrm{kg} / \mathrm{m} 2)$, mean $\pm \mathrm{SD}$ & $27.15 \pm 4.87$ & $25.45 \pm 4.89$ & n.s. \\
\hline Waist circumference $(\mathrm{cm})$, mean $\pm \mathrm{SD}$ & $95.40 \pm 13.62$ & $84.54 \pm 13.62$ & $<0.001$ \\
\hline Triglycerides $(\mathrm{mmol} / \mathrm{l})$, mean \pm SD & $1.66 \pm 0.90$ & $1.43 \pm 0.97$ & 0.014 \\
\hline HDL-C $(\mathrm{mmol} / \mathrm{l})$, mean \pm SD & $1.17 \pm 0.31$ & $1.35 \pm 0.42$ & $<0.001$ \\
\hline Systolic blood pressure $(\mathrm{mmHg})$, mean $\pm \mathrm{SD}$ & $132.08 \pm 17.59$ & $119.00 \pm 11.61$ & $<0.001$ \\
\hline Diastolic blood pressure $(\mathrm{mmHg})$, mean $\pm \mathrm{SD}$ & $80.62 \pm 10.62$ & $75.04 \pm 8.27$ & $<0.001$ \\
\hline Blood glucose $(\mathrm{mmol} / \mathrm{l})$, mean $\pm \mathrm{SD}$ & $5.16 \pm 2.03$ & $4.84 \pm 1.36$ & n.s. \\
\hline C-reactive protein $(\mathrm{mg} / \mathrm{l})$, mean $\pm \mathrm{SD}$ & $6.51 \pm 13.14$ & $1.62 \pm 1.62$ & 0.002 \\
\hline
\end{tabular}

HDL-C: high-density lipoprotein cholesterol; n.s.: non significant.

TABLE 2: Metabolic syndrome and its components in patients with overall, mild, moderate and severe psoriasis and controls

\begin{tabular}{|c|c|c|c|c|c|c|c|c|c|}
\hline Variable, n (\%) & $\begin{array}{l}\text { Controls } \\
(\mathrm{n}=163)\end{array}$ & $\begin{array}{l}\text { Overall } \\
\text { psoriasis } \\
(\mathrm{n}=244)\end{array}$ & $\mathbf{P}$ & $\begin{array}{l}\text { Mild } \\
\text { psoriasis } \\
(\mathrm{n}=75)\end{array}$ & $\mathbf{P}$ & $\begin{array}{l}\text { Moderate } \\
\text { psoriasis } \\
(\mathrm{n}=84)\end{array}$ & $\mathbf{P}$ & $\begin{array}{l}\text { Severe } \\
\text { psoriasis } \\
(n=85)\end{array}$ & $\mathbf{P}$ \\
\hline $\begin{array}{l}\text { Waist circumference } \geq 102 \mathrm{~cm} \text { (men) } \\
\text { and } \geq 88 \mathrm{~cm} \text { (women) }\end{array}$ & $43(26.4)$ & $114(46.7)$ & $<0.001$ & $31(41.3)$ & 0.021 & $44(52.4)$ & $<0.001$ & $39(45.9)$ & 0.002 \\
\hline Triglycerides $\geq 1.7 \mathrm{mmol} / \mathrm{L}$ & $40(24.5)$ & 93 (38.1) & 0.004 & $28(37.3)$ & 0.042 & 37 (44.0) & 0.002 & $28(32.9)$ & 0.159 \\
\hline $\begin{array}{l}\text { HDL-C }<1.03 \mathrm{mmol} / \mathrm{L} \text { (men) and } \\
<1.29 \mathrm{mmol} / \mathrm{L} \text { (women) }\end{array}$ & $64(39.5)$ & $117(48.1)$ & 0.087 & $30(40.5)$ & 0.880 & $41(48.8)$ & 0.162 & $46(54.1)$ & 0.028 \\
\hline $\begin{array}{l}\mathrm{BP} \text { (systolic } \geq 130 \mathrm{mmHg} \text { or diastolic } \\
\geq 85 \mathrm{mmHg} \text { ) }\end{array}$ & $42(25.8)$ & $164(67.2)$ & $<0.001$ & $49(65.3)$ & $<0.001$ & $61(72.6)$ & $<0.001$ & $54(63.5)$ & $<0.001$ \\
\hline $\begin{array}{l}\text { Blood glucose } \geq 5.6 \mathrm{mmol} / \mathrm{L} \text { or } \mathrm{DM} \\
\text { type } 2\end{array}$ & $22(13.5)$ & 77 (31.6) & $<0.001$ & $18(24.0)$ & 0.044 & $26(31.0)$ & 0.001 & $33(38.8)$ & $<0.001$ \\
\hline Metabolic syndrome & $32(19.6)$ & $110(45.1)$ & $<0.001$ & $30(40.0)$ & 0.001 & $44(52.4)$ & $<0.001$ & $36(42.4)$ & $<0.001$ \\
\hline $\begin{array}{l}\text { Components of metabolic syndrome } \\
(\text { mean } \pm \text { SD) }\end{array}$ & $1.29 \pm 1.30$ & $2.32 \pm 1.37$ & $<0.001$ & $2.08 \pm 1.43$ & $<0.001$ & $2.49 \pm 1.36$ & $<0.001$ & $2.35 \pm 1.32$ & $<0.001$ \\
\hline
\end{tabular}

HDL-C: high-density lipoprotein cholesterol; BP: blood pressure; DM: diabetes mellitus. 
Comparing psoriatic patients with and without MetS, we observed that patients with MetS had a higher mean age, a later onset of psoriasis, longer disease duration and were less physically active (Table 4). There were no differences between two groups of patients regarding gender, smoking habits, and severity of disease.

According to multivariate logistic regression analysis (Table 5) only later onset (OR 1.03, 95\% CI 1.01-1.05) and longer duration of psoriasis (OR 1.05, 95\% CI 1.02-1.08) were independent predictive factors for MetS. The Hosmer-Lemeshow statistic indicates a poor fit if the significance value is less than 0.05 (H-L test $=13.416$; df $=8 ; \mathrm{p}=0.198)$. $\mathrm{AUC}=0.658(95 \% \mathrm{CI} 0.590-0.726 ; \mathrm{p}=0.000)$.

\section{DISCUSSION}

In the present study we have found significantly higher prevalence of MetS in psoriatic patients compared with controls $(45.1 \%$ vs. $19.6 \%)$ that is in accordance with a number of studies conducted in diverse geographic locations and different nations. ${ }^{12,14,15,18-24}$ In contrast, several other studies have shown no significant difference in the prevalence of MetS between psoriasis patients and controls. ${ }^{20,25,26}$ These conflicting findings may be due to different criteria applied in assessing MetS, different racial/ethnic and genetic background and different lifestyles in different nations.

A number of authors found that the severity of psoriasis is associated with MetS in a "dose-response" manner, from mild to severe psoriasis. ${ }^{14,27,28}$ Sommer et al. observed that the risk of MetS was high only in patients with severe psoriasis, suggesting that the occurrence of cardiovascular complications like coronary heart dis- ease is restricted to the severe form of psoriasis. ${ }^{19}$

However, like in several other studies ${ }^{13,15,18,26,29}$ we failed to find any association between severity of psoriasis and MetS. Such finding suggests that psoriatic patients with mild or moderate disease might share a similar possibility to develop the cardio-metabolic risk factors like patients with severe disease.

There is substantial evidence from reported studies linking psoriasis with core MetS components, such as hypertension, central obesity, and DM. ${ }^{14,30,31}$

High blood pressure was the most frequent component of MetS in our psoriatic patients and its prevalence differs significantly between psoriatic patients and patients in the control group $(67.2 \%$ vs. $25.8 \%$ ), but there were no differences according to disease severity. In a large population based study, although the risk for other cardiovascular risk factors was higher in severe psoriasis, a similar association between psoriasis severity and risk of hypertension was

TABLE 5: Multivariate logistic regression analysis for prediction of metabolic syndrome in psoriatic patients

\begin{tabular}{llll} 
Variable & Odds ratio & $\mathbf{9 5 \%}$ CI & P \\
\hline Later onset of psoriasis & 1.03 & $1.01-1.05$ & 0.002 \\
Longer duration of psoriasis & 1.05 & $1.02-1.08$ & 0.001 \\
Physical activity & 0.70 & $0.46-1.07$ & 0.103 \\
PASI & 1.00 & $0.98-1.02$ & 0.936 \\
\hline
\end{tabular}

PASI: psoriasis area and severity index.

Hosmer-Lemeshow $(\mathrm{H}-\mathrm{L})$ test $=13.416 ; \mathrm{df}=8 ; \mathrm{p}=0.198$. Area under the ROC curve (AUC) $=0.658(95 \%$ CI $0.590-0.726 ; p=0.000$

TABLE 3: Association between psoriasis severity and metabolic syndrome and its components adjusted on age and sex

\begin{tabular}{|c|c|c|c|c|c|c|}
\hline & $\begin{array}{l}\text { Abdominal } \\
\text { obesity } \\
\text { OR }(95 \% \mathrm{CI})\end{array}$ & $\begin{array}{l}\text { Raised triglyceride } \\
\text { levels } \\
\text { OR ( } 95 \% \text { CI })\end{array}$ & $\begin{array}{l}\text { Low HDL-C } \\
\text { OR }(95 \% \mathrm{CI})\end{array}$ & $\begin{array}{l}\text { High blood } \\
\text { pressure } \\
\text { OR }(95 \% \mathrm{CI})\end{array}$ & $\begin{array}{l}\text { Hyperglycemia } \\
\text { OR }(95 \% \text { CI })\end{array}$ & $\begin{array}{l}\text { Metabolic } \\
\text { Syndrome } \\
\text { OR }(95 \% \mathrm{CI})\end{array}$ \\
\hline No psoriasis, $n=163$ & 1.00 & 1.00 & 1.00 & 1.00 & 1.00 & 1.00 \\
\hline $\begin{array}{l}\text { Psoriasis overall, } \mathrm{n}=244 \\
\text { By extent }\end{array}$ & $2.29(1.39-3.78)$ & $1.42(0.87-1.04)$ & $1.87(1.18-2.96)$ & $3.81(2.30-6.31)$ & $1.92(1.08-3.41)$ & $2.66(1.58-4.42)$ \\
\hline $\begin{array}{l}\text { Mild psoriasis }(\text { PASI }<10), \\
\mathrm{n}=75\end{array}$ & $1.92(1.02-3.63)$ & $1.44(0.78-2.68)$ & $1.34(0.74-2.43)$ & $4.24(2.17-8.32)$ & $1.40(0.66-2.96)$ & $2.28(1.19-4.35)$ \\
\hline $\begin{array}{l}\text { Moderate psoriasis (PASI: } \\
10-20), n=84\end{array}$ & $2.53(1.36-4.71)$ & $1.75(0.96-3.19)$ & $1.88(1.05-3.37)$ & $4.45(2.29-8.63)$ & $1.70(0.84-3.43)$ & $3.21(1.72-6.02)$ \\
\hline $\begin{array}{l}\text { Severe psoriasis }(\text { PASI } \geq 20 \text { ), } \\
n=85\end{array}$ & $2.48(1.32-4.68)$ & $1.10(0.59-2.06)$ & $2.63(1.45-4.77)$ & $2.93(1.54-5.61)$ & $2.80(1.41-5.54)$ & $2.46(1.29-4.66)$ \\
\hline
\end{tabular}

TABLE 4: Descriptive characteristics of psoriatic patients with and without metabolic syndrome

\begin{tabular}{|c|c|c|c|}
\hline Factor & $\begin{array}{l}\text { Psoriatic patients with } \\
\text { metabolic syndrome }(n=110)\end{array}$ & $\begin{array}{l}\text { Psoriatic patients without } \\
\text { metabolic syndrome }(n=134)\end{array}$ & $\mathbf{P}$ \\
\hline Sex (males/females) & $70 / 44$ & $90 / 44$ & 0.564 \\
\hline Age at enrolment (years), mean \pm SD & $56.61 \pm 12.11$ & $45.83 \pm 16.14$ & 0.000 \\
\hline Age at onset of psoriasis (years), mean \pm SD & $39.86 \pm 15.78$ & $35.08 \pm 16.95$ & 0.023 \\
\hline Duration of psoriasis (years), mean $\pm \mathrm{SD}$ & $18.25 \pm 12.38$ & $14.71 \pm 11.71$ & 0.025 \\
\hline Smoking, n (\%) & $41(37.3)$ & $62(46.3)$ & 0.157 \\
\hline Physical activity, n (\%) & $33(30.0)$ & $64(47.8)$ & 0.005 \\
\hline PASI, mean \pm SD & $17.75 \pm 11.71$ & $17.11 \pm 11.49$ & 0.670 \\
\hline PASI > 20, n (\%) & $36(42.4)$ & $49(57.6)$ & 0.531 \\
\hline $\mathrm{BSA}$, mean $\pm \mathrm{SD}$ & $1.75 \pm 0.43$ & $1.65 \pm 0.48$ & 0.080 \\
\hline $\mathrm{BSA}>10, \mathrm{n}(\%)$ & $86(65.2)$ & $83(75.5)$ & 0.082 \\
\hline
\end{tabular}

PASI: psoriasis area and severity index; BSA: body surface area. 
not found. ${ }^{28}$ Such finding can draw attention not only to the patients with severe, but also to the patients with moderate or mild form of psoriasis, implicating that inflammation could be present and important in the development of comorbidities although the lesions are not widespreading.

However, the largest systematic review and meta-analysis performed to date, with over 309,000 psoriatic patients, revealed that psoriasis was associated with greater prevalence of hypertension and that patients with severe psoriasis had greater odds of hypertension than those with mild psoriasis. ${ }^{30}$ The exact mechanism underlying this association is still unknown. Although psoriasis and hypertension have same risk factors such as smoking and obesity, previous studies have shown an independent association between psoriasis and hypertension after adjusting on these factors. ${ }^{30}$

Like in a number of previous reports we found that psoriasis was independently associated with an increased prevalence of type 2 DM. ${ }^{22,28,32-34}$ In our study an increased risk of DM was observed only in patients with severe psoriasis. A recent large systematic review and meta analysis of observational studies concluded that psoriasis was associated with a $59 \%$ increased prevalence of DM (OR 1.59, 95\% CI 1.38-1.83) and a 27\% increased risk (OR 1.27, 95\% CI 1.16-1.40) of developing DM among patients with psoriasis. Patients with severe psoriasis may have even higher risk of developing DM. ${ }^{31}$ This consistent association between psoriasis and DM suggests a likely pathophysiologic link between the two diseases. It is believed that insulin resistance underlies the pathogenesis of the MetS. However, the relation between psoriasis and insulin resistance/DM remains to be elucidated. ${ }^{22}$

Our finding that the prevalence of abdominal obesity is significantly higher in psoriatic patients compared with controls is consistent with previous observations. ${ }^{12,14,18,19,28,34-36}$ However, it has been debated whether obesity precedes the development of psoriasis or it is a consequence of psoriasis. ${ }^{37-39}$ Evidence suggests that depression poor nutrition habits, lack of physical activity, alcohol consumption, stress and chronic inflammation have all been linked to psoriasis and favor obesity. In turn, obesity as a proinflammatory state, associated with increased levels of inflammatory factors such as tumor necrosis factor-alpha, and interleukin 6 , can favor psoriasis. ${ }^{12}$

Hypertrigliceridemia and low level of HDL-C were more prevalent in psoriatic patients (38.1\% and $48.1 \%$ respectively) than in control group (24.5\% and $39.5 \%$ respectively), but significant difference between two groups was obtained only for high triglyceride levels. Several studies suggested the relation between psoriasis and atherogenic dyslipidemia including increased levels of total cholesterol, triglycerides, low-density lipoprotein [LDL], very LDL and lipoprotein A, and low HDL and apolipoprotein B. ${ }^{16,22}$ Some authors concluded that abnormalities in lipid metabolism in psoriatic patients may be genetically determined. ${ }^{39}$

Like in several previous studies elevated CRP as key biomarker of systemic inflammation and risk for future vascular disease was more prevalent in psoriatic patients compared with controls. ${ }^{12,19,39,40}$

In this study smoking was found to be more prevalent in patients with psoriasis than in controls, that is in accordance with previous findings. ${ }^{37,38}$ A recent large systematic review and meta-analysis revealed an association between psoriasis and smoking, suggesting that smoking is an independent factor for the development of psoriasis. ${ }^{41}$ However, like in several previous studies we did not find any statistically significant difference in smoking habits between psoriatic patients with and without MetS. ${ }^{18,39}$

In our study physical inactivity was observed more frequently in patients with psoriasis compared to controls. Psoriatic patients with MetS were less physically active than those without MetS, but we failed to find an independent relationship between two variables. It is known that lack of physical activity may contribute to the increased risk of CVD in psoriasis patients. Recent evidence suggests shared pathophysiological pathways between psoriasis, its cardiometabolic comorbidities, and physical activity. ${ }^{42}$

Later onset and longer duration of psoriasis were independent predicting factors of MetS in our patients. We do not have any explanation why later onset of psoriasis, rather than an early onset, was associated with MetS. However, the association of a longer disease duration and MetS already reported by Gisondi et al. ${ }^{18}$ and Nisa and Qazi $^{29}$ could be explained with long-lasting chronic inflammation and all its aforementioned consequences.

To the best of our knowledge, this is the first study in Southeastern Europe to report the relation between psoriasis and MetS. Unlike in many population-based studies in which the diagnosis of psoriasis was self-reported in our study it was confirmed by experienced dermatologists. Selection and information bias are unlikely to explain our results as the patients with psoriasis and control subjects were identified and included from the same hospital and data from all participants were collected in the same manner by experienced dermatologists. Study findings were based on direct measurement (laboratory values) of the components of MetS, and objectively measured psoriasis severity. In addition we used standard criteria for diagnosis of MetS.

However, several limitations of the present study should be mentioned. First, the cross-sectional design of the study does not allow us to draw directional causal inferences concerning the association between psoriasis and MetS. Second, factors such as diet, alcohol consumption or mental health, which have not been evaluated in this study, may be confounders in this relation. Thirdly, all patients were from a tertiary referral psoriasis centre and consequently a significant portion of patients with severe psoriasis was recruited. Therefore results may not be transferable to other settings.

\section{CONCLUSION}

Our findings demonstrate a strong association between psoriasis and MetS and its components, regardless of psoriasis severity.

Although questions such as whether psoriasis predisposes the patient to MetS or whether metabolic disorders can lead to psoriasis have remained unanswered, the higher prevalence of MetS in patients with psoriasis reported by most studies emphasizes the need for early detection of metabolic disorders and adequate early treatment of psoriasis and its comorbidities through a multidisciplinary approach. ${ }^{43}$ Patients with psoriasis should be encouraged to address aggressively their modifiable cardiovascular risk factors, in particular hypertension, obesity, physical inactivity, and smoking habits. $\square$ 


\section{REFERENCES}

1. Gisondi P, Ferrazzi A, Girolomoni G. Metabolic Comorbidities and Psoriasis. Acta Dermatovenerol Croat. 2010;18:297-304.

2. Kim N, Thrash B, Menter A. Comorbidities in Psoriasis patients. Semin Cutan Med Surg. 2010;29:10-5

3. de Korte J, Sprangers MA, Mombers FM, Bos JD. Quality of life in patients with psoriasis: a systematic literature review. J Investig Dermatol Symp Proc. 2004;9:140-7.

4. Milčić $\mathrm{D}$, Janković $\mathrm{S}$, Vesić $\mathrm{S}$, Milinković $\mathrm{M}$, Janković J. Assessment of quality of life in patients with psoriasis: a study from Serbia. Int J Dermatol. 2015;54:523-8.

5. Jankovic S, Raznatovic M, Marinkovic J, Jankovic J, Kocev N, Tomic-Spiric V, et al. Health-Realted Quality of Life in patients with psoriasis. J Cutan Med Surg. 2011;15:29-36.

6. Ryan C, Kirby B. Psoriasis is a systemic disease with multiple cardiovascular and metabolic comorbidities. Dermatol Clin. 2015;33:41-55.

7. Baeta IG, Bittencourt FV, Gontijo B, Goulart EM. Comorbidities and cardiovascular risk factors in patients with psoriasis. An Bras Dermatol. 2014;89:735-44.

8. Gelfand JM, Neimann AL, Shin DB, Wang X, Margolis DJ, Troxel AB. Risk of myocardial infarction in patients with psoriasis. JAMA. 2006;296:1735-41.

9. Gelfand JM, Dommasch ED, Shin DB, Azfar RS, Kurd SK, Wang X, et al. The risk of stroke in patients with psoriasis. J Invest Dermatol. 2009;129:2411-8.

10. Gelfand JM, Troxel AB, Lewis JD, Kurd SK, Shin DB, Wang X, et al. The risk of mortality in patients with psoriasis: results from a population-based study. Arch Dermatol. 2007;143:1493-9.

11. National Cholesterol Education Program (NCEP) Expert Panel on Detection, Evaluation, and Treatment of High Blood Cholesterol in Adults (Adult TreatmentPanel III). Third Report of the National Cholesterol Education Program (NCEP) Expert Panel on Detection, Evaluation, and Treatment of High Blood Cholesterol in Adults (Adult Treatment Panel III) final report. Circulation. 2002;106:3143-421.

12. Love TJ, Qureshi AA, Karlson EW, Gelfand JM, Choi HK. Prevalence of the Metabolic Syndrome in psoriasis: Results from the National Health and Nutrition Examination Survey, 2003-2006. Arch Dermatol. 2011;147:419-24.

13. Mebazaa A, El Asmi M, Zidi W, Zayani Y, Cheikh Rouhou R, El Ounifi S, et al. Metabolic syndrome in Tunisian psoriatic patients: prevalence and determinants. J Eur Acad Dermatol Venereol. 2011;25:705-9.

14. Langan SM, Seminara NM, Shin DB, Troxel AB, Kimmel SE, Mehta NN, et al. Prevalence of metabolic syndrome in patients with psoriasis: A population-based study in the United Kingdom. J Invest Dermatol. 2012;132:556-62.

15. Miller IM, Ellervik C, Zarchi K, Ibler KS, Vinding GR, Knudsen KM, et al. The association of metabolic syndrome and psoriasis: a population- and hospitalbased cross-sectional study. J Eur Acad Dermatol Venereol. 2015;29:490-7.

16. Alsufyani MA, Golant AK, Lebwohl M. Psoriasis and the metabolic syndrome. Dermatol Ther. 2010;23:137-43.

17. Naldi L. Scoring and monitoring the severity of psoriasis. What is the preferred method? What is the ideal method? Is PASI passé? Facts and controversies. Clin Dermatol. 2010;28:67-72.

18. Gisondi P, Tessari G, Conti A, Piaserico S, Schianchi S, Peserico A, et al. Prevalence of metabolic syndrome in patients with psoriasis: a hospital based case-control study. Br J Dermatol. 2007;157:68-73.

19. Sommer DM, Jenisch S, Suchan M, Christophers E, Weichenthal M. Increased prevalence of the metabolic syndrome in patients with moderate to severe psoriasis. Arch Dermatol Res. 2006;298:321-8.

20. Takahashi H, Takahashi I, Honma M, Ishida-Yamamoto A, lizuka H. Prevalence of metabolic syndrome in Japanese psoriasis patients. J Dermatol Sci. 2010;57:143-4.

21. Madanagobalane S, Anandan S. Prevalence of metabolic syndrome in south Indian patients with psoriasis vulgaris and the relation between disease severity and metabolic syndrome: A hospital-based case control study. Indian J Dermatol. 2012;57:353-7.

22. Takahashi $H$, lizuka $H$. Psoriasis and metabolic syndrome. J Dermatol. 2012:39:212-8.

23. Zindancı I, Albayrak O, Kavala M, Kocaturk E, Can B, Sudogan S, et al. Prevalence of Metabolic Syndrome in Patients with Psoriasis. Scientific World Journal. 2012;2012:312463.

24. Armstrong AW, Harskamp CT, Armstrong EJ. Psoriasis and metabolic syndrome: A systematic review and meta/analysis of observational studies. J Am Acad Dermatol. 2013;68:654-62.
25. Chen YJ, Wu CY, Shen JL, Chu SY, Chen CK, Chang YT, et al. Psoriasis independently associated with hyperleptinemia contributing to metabolic syndrome. Arch Dermatol. 2008;144:1571-5.

26. Kim GW, Park HJ, Kim HS, Kim SH, Ko HC, Kim BS, et al. Analysis of cardiovascular risk factors and metabolic syndrome in korean patients with psoriasis. Ann Dermatol. 2012;24:11-5.

27. Choi WJ, Park EJ, Kwon IH, Kim KH, Kim KJ. Association between psoriasis and cardiovascular risk factors in Korean patients. Ann Dermatol. 2010;22:300-6.

28. Neimann AL, Shin DB, Wang X, Margolis DJ, Troxel AB, Gelfand JM. Prevalence of cardiovascular risk factors in patients with psoriasis. J Am Acad Dermatol. 2006:55:829-35.

29. Nisa N, Qazi MA. Prevalence of metabolic syndrome in patients with psoriasis Indian J Dermatol Venereol Leprol. 2010:76:662-5.

30. Armstrong AW, Harskamp CT, Armstrong EJ. The association between psoriasis and hypertension: a systematic review and meta-analysis of observational studies. J Hypertens. 2013;31:433-42.

31. Armstrong AW, Harskamp CT, Armstrong EJ. Psoriasis and the risk of diabetes mellitus: a systematic review and meta-analysis. JAMA Dermatol. 2013;149:8491.

32. Brauchli YB, Jick SS, Meier CR. Psoriasis and the risk of incident diabetes mellitus: a population-based study. Br J Dermatol.30. Armstrong AW, Harskamp $\mathrm{CT}$, Armstrong EJ. The association between psoriasis and hypertension: a 2008;159:1331-7.

33. Cohen AD, Dreiher J, Shapiro Y, Vidavsky L, Vardy DA, Davidovici B, et al. Psoriasis and diabetes: A population-based cross-sectional study. J Eur Acad Dermatol Venereol. 2008:22:585-9.

34. Qureshi AA, Choi HK, Setty AR, Curhan GC. Psoriasis and the risk of diabetes and hypertension: a prospective study of US female nurses. Arch Dermatol. 2009;145:379-82.

35. Takahashi H, Tsuji H, Takahashi I, Hashimoto Y, Ishida-Yamamoto A, lizuka H. Prevalence of obesity/adiposity in Japanese psoriasis patients: adiposity is correlated with the severity of psoriasis. J Dermatol Sci. 2009:55:74-6.

36. Prey S, Paul C, Bronsard V, Puzenat E, Gourraud PA, Aractingi S, et al. Cardiovascular risk factors in patients with plaque psoriasis: a systematic review of epidemiological studies. J Eur Acad Dermatol Venereol. 2010;24:23-30.

37. Naldi L, Chatenoud L, Linder D, Belloni Fortina A, Peserico A, Virgili AR, et al. Cigarette smoking, body mass index, and stressful life events as risk factors for psoriasis: results from an Italian case-control study. J Invest Dermatol. 2005;125:61-7.

38. Herron MD, Hinckley M, Hoffman MS, Papenfuss J, Hansen CB, Callis KP, et al The impact of obesity and smoking on psoriasis presentation and management. Arch Dermatol. 2005;141:1527-34.

39. Mallbris L, Granath F, Hamsten A, Ståhle M. Psoriasis is associated with lipid abnormalities at the onset of skin disease. J Am Acad Dermatol. 2006;54:614-21.

40. Chodorowska G, Wojnowska D, Juszkiewicz-Borowiec M. C-reactive protein and alpha 2-macroglobulin plasma activity in medium-severe and severe psoriasis. J Eur Acad Dermatol Venereol. 2004;18:180-3.

41. Armstrong AW, Harskamp CT, Dhillon JS, Armstrong EJ. Psoriasis and smoking: a systematic review and meta-analysis. Br J Dermatol. 2014;170:304-14.

42. Wilson PB, Bohjanen KA, Ingraham SJ, Leon AS. Psoriasis and physical activity: a review. J Eur Acad Dermatol Venereol. 2012;26:1345-53

43. Azfar RS, Gelfand JM. Psoriasis and metabolic disease: epidemiology and pathophysiology. Curr Opin Rheumatol. 2008;20:416-22.

\begin{tabular}{l}
\hline MAILING ADDRESS: \\
Slavenka Janković \\
Institute of Epidemiology, \\
Faculty of Medicine, \\
University of Belgrade, \\
Višegradska 26, \\
11000 Belgrade \\
Serbia \\
Email: slavenkaj@gmail.com
\end{tabular}

How to cite this article: Milčić D, Janković S, Vesić S, Milinković M, Marinković J, Ćirković A, Janković J. Prevalence of metabolic syndrome in patients with psoriasis: a hospital-based cross-sectional study. An Bras Dermatol. 2017;92(1):46-51. 